\title{
Conversion of Organic Waste into Electricity
}

\author{
Mrs.A.Santhi MaryAntony ${ }^{1}$, Mrs.D.Ramya ${ }^{2}$, Dr.D.Godwin Immanuel ${ }^{3}$ \\ \{msanthimary@gmail.com ${ }^{1}$, ramya.devasahayagam@gmail.com² ${ }^{2}$,godwinimmanuel@gmail.com $\left.{ }^{3}\right\}$ \\ ${ }^{1,2}$ Assistant Professor, ${ }^{3}$ Associate Professor, ${ }^{1,2,3}$ Department of Electrical and Electronics, \\ ${ }^{1,2,3}$ Sathyabama Institute of Science and Technology, Chennai.
}

\begin{abstract}
Power generation from natural resources are very important as overall power generation capability has been depleting. Many natural resources are for the generation of power such as renewable energy sources, energy generated from the waste food materials etc. This paper work aims in generating the power from the organic food waste. Now day's organic waste food is available in surplus quantity. The organic waste food is stored in the storage tank. From the storage tank it is crushed and fed into the mixer tank and then to the digester. The crushed organic waste is kept in the Digester for about than twenty days. The collected gas in the cylinder is filtered by using a carbon filter and fed to the generator. The generator generates the electricity. By using this flow process organic waste is converted into electricity. In this paper, a prototype is also installed for $10 \mathrm{Kg}$ of organic waste from which $20 \mathrm{KW}$ of power is generated.
\end{abstract}

Keywords: Renewable energy, Biogas, Anaerobic Digestion, Digestion Technology, Biogas, Fertilizers, Digestate, Combustible mixture.

\section{Introduction}

The biogas system must be designed specially and should have prior attention that is familiar with the technology [1]. The digester should be operated properly according to the usage and should be maintained carefully at regular intervals. The generation of gas is a chemical process where the organic matter gets decomposed [2].

The biodegradable organic wastes are processed in the digester for generation of gas in the gas cylinder [3]. When organic matter such as mentioned is digested an aerobically, a highly combustible mixture of gases [4]. This compromise of $60 \%$ of methane, $32 \%$ of $\mathrm{CO}_{2}$, $5 \%$ of $\mathrm{NO}_{2}$ and traces of $\mathrm{SO}_{2}$ and some gases.

Bio waste is crushed into small pieces and fed into digestive processor. Slurrifying means adding liquid to the bio waste to form it easier to process [5]. In Fig. 1 Bio gas based power generation plant is shown in detail for generation of electricity from the organic waste [7]. Microbes need warm conditions; therefore, the bio waste is set up in hot condition. The bio gas production from the digester through the gas cylinder takes about 4-5 weeks. The gas obtained from the gas cylinder is fed to the generator for generation of electricity from the organic waste [8]. Further the waste from digester is fed to the outlet tank. The organic waste is decomposed and the decomposed particles are used for an organic fertilizer for fields [9]. Digestates are well used for fertilisation of fields. 


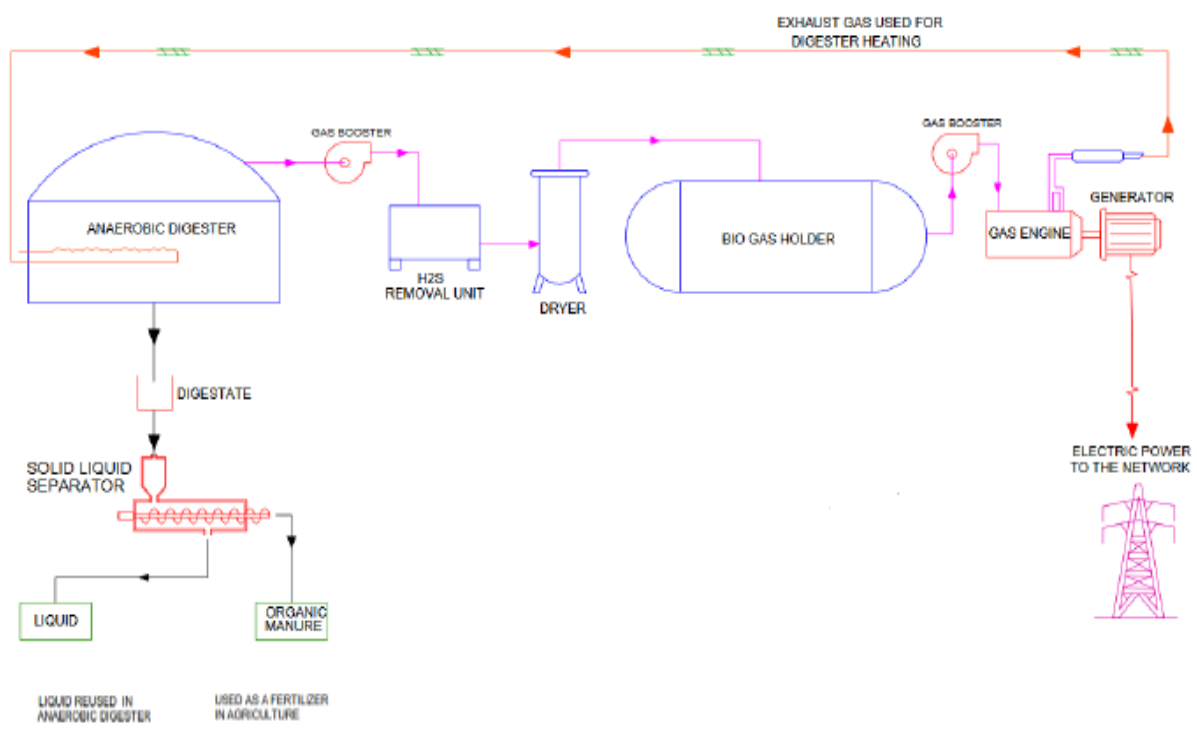

Fig. 1. Biogas Based Power Generation Plant 


\section{Flow chart for Biogas Production}

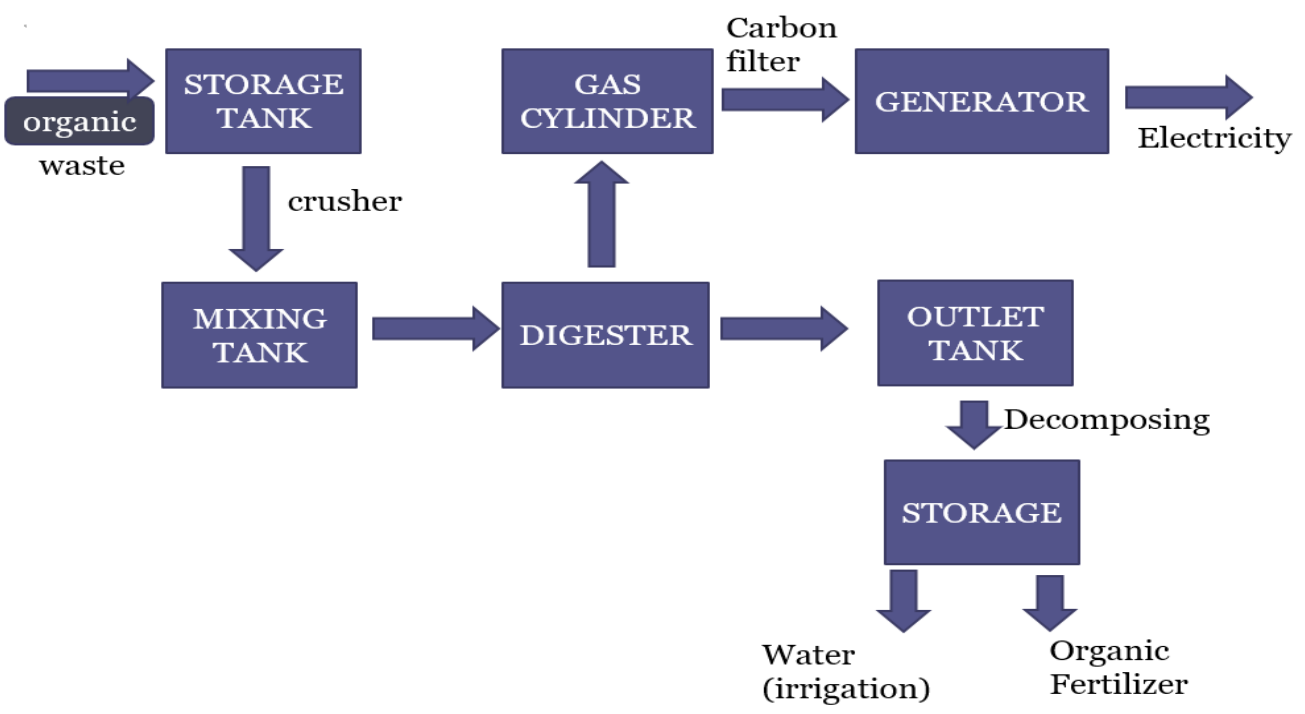

Fig. 2. Flowchart for Bio Gas Production

The organic wastes are collected and send to the storage tank. In the mixing tank the organic food materials are crushed by adding adequate quantity of water. The mixing tank converts the organic waste in its semi solid liquid form by addition of water in it. The mixture is fed to the digester unit. The digester is an important unit in the biogas generation. In the digester the mixture is missed well from which methane gas, carbon gas, Hydrogen Sulphide gas etc. are generator from the top outlet of the digester from which it is fed to the gas cylinder. Hence gas cylinder consists of a mixture of Methane gas, Carbon gas, Hydrogen Sulphide etc. The gas used for the generation of biogas is the methane gas. By using a carbon filter at the outlet of the gas cylinder, methane gas is generated. The generated Methane gas is led to the generator from which, electricity is generated as shown in Fig. 2. The organic waste left in the digester is further decomposed and utilised as organic fertilizers for the fields during the agriculture. The remaining watery liquid is also used for irrigation purposes.

\section{Experimental Setup}

An experimental set up had erected in the college campus near to the food mess area. The wastage of organic food every day is dumped in the storage tank for generation of biogas for electricity. The gas produced is processed through carbon filter to remove unwanted gas and carbon dioxide. According to the specification of the bio plant, an approximate amount of organic waste can be originated from the digester as shown in Fig. 3.

Steps followed for converting the organic waste into bio gas for power generation 
1. The organic waste of about $100 \mathrm{~kg}$ is led into the storage tank.

2. The organic waste along with the water (liquid) is well crushed in the mixing tank. The mixture is allowed to remain in the mixing tank for 2-3 days.

3. The semi liquid mixture consists of Methane, Carbon, Hydrogen Sulphide etc which is fed to the Gas Cylinder. The top outlet of the digester is connected to the gas cylinder form which the gases obtained for the digester reaches the gas cylinder.

4. The other gases are removed by using a carbon filter at the outlet of gas cylinder.

5. The methane gas produced for the outlet of gas cylinder is led to the generator. The bio gas in the generator is converted into electricity.

6 . The above mentioned steps are repeated at regular intervals for efficient generation of electricity.
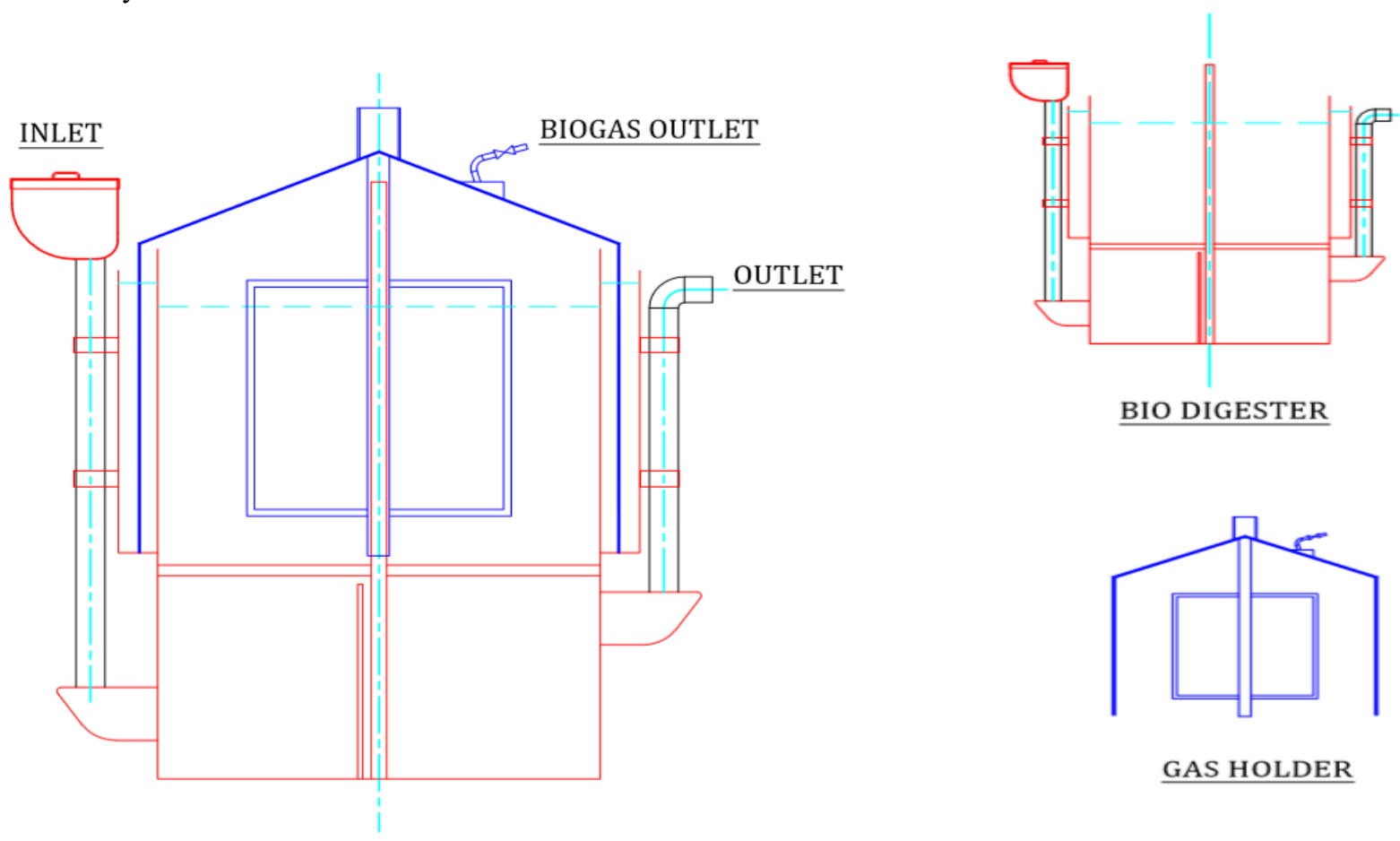

Fig. 3. Experimental Set up for Biogas generation

\section{Results and discussions}

The final output obtained is a clean source of energy that intends to make a minimum impact on carbon society. The fuel can be thus stored and used for various purposes. The gas obtained can be used as an alternative to fossil fuels [6]. This can also replace the available renewable resources like solar power plants and wind power. The cost of operation and installation solar panel and wind power is more as compared to the biogas power plant as shown in Table 1.

Table 1. Comparsion table for different types of energy sources 


\begin{tabular}{|c|c|c|c|}
\hline$\frac{\text { Types Of }}{\underline{\text { Energy }}}$ & Biogas Plant & $\underline{\text { Solar Power Plant }}$ & $\underline{\text { Wind Energy }}$ \\
\hline Source & $\begin{array}{l}\text { Organic feedstock } \\
\text { And operator }\end{array}$ & Sunlight and solar panels & Wind turbine \\
\hline Efficiency & $\begin{array}{c}\text { Generators can run } \\
24 \mathrm{hrs}\end{array}$ & $\begin{array}{l}\text { Only during the sun } \\
\text { shines }\end{array}$ & $\begin{array}{c}\text { Only when the wind } \\
\text { blows }\end{array}$ \\
\hline $\begin{array}{l}\text { Operational } \\
\text { Cost }\end{array}$ & A manpower & No need & No need \\
\hline Battery Backup & $\begin{array}{c}\text { Can give 6-8 hrs per } \\
\text { day }\end{array}$ & $1-2$ days & $1-2$ days \\
\hline Production & $\begin{array}{l}\text { Gas, electricity and } \\
\text { fertilizer }\end{array}$ & Electricity & Electricity \\
\hline Cost & $60 \mathrm{k}$ & $90 \mathrm{k}$ & 11 \\
\hline
\end{tabular}

So, In terms of economical and socially biogas plant is best as compared to the other renewable sources. Its best use is made in rural areas where the availability of electricity is a problem.

\section{Conclusions}

As referred to the current scenario $10 \%$ of power is generated from the organic waste. The production of biogas is very simple when compared to the conventional renewable energy sources. The power generated from the organic waste can be implemented in the remote areas because the waste obtained after bio gas generation can be decomposed and utilised as an organic fertilizers and remaining organic water is used for irrigation in fields. The Installation cost setup is very less when compared to the setup of renewable energy sources. The experimental set up of $100 \mathrm{Kg}$ can generate 9 cubic meter methane gas and $2000 \mathrm{KW}$ electricity in a day. When the availability of organic waste is more than more biogas can be generated. Hence when the demand of energy increases then it could be biogas demand also will be increased. As our country is leading towards demand of power generation, in future the fossil fuels will be replaced by the Bio gas generation. With the development of technology future world will be focussed on to the power generation from the organic waste. Hence power generation from Bio gas will be a very important technique to meet power demand as the energy demand are increasing very rapidly. The setup cost and maintenance is reduced when 
compared to power generated from fossil fuels, PV system, Wind energy conversion system etc.

\section{REFERENCES}

[1] Adelekan B.A., "Assessing Nigeria's Agricultural Biomass Potential as a Supplementary Energy Resource through Adoption of Biogas Technology", Nigeria Journal of Renewable Energy", Vol.10, No.1, 2002, pp. 145-150.

[2] P Illavarason, Renjith J Arokia, P Mohan Kumar, 2019, "Comparative study and an improved algorithm for iris and eye corner detection in real time application" Computer-Aided Developments: Electronics and Communication, CRC Press, PP-91-98.

[3] Ezekoye, V.A and Okeke C.E "Design, construction, and performance evaluation of plastic biodigester and the storage of biogas", Pacific journal of science and Technology, 2006, pp 176-184.

[4] Smith, W.H., Wilkie, A.C. and Smith, P.H. "Methane from biomass and waste - a program review". TIDE , 1992, pp 1-20.

[5] Tower P., Lombard, "New Landfill Gas Treatment Technology Dramatically Lowers Energy Production Costs" Applied Filter Technology, March 2012.

[6] Waqar Bhatti, M. "Mini biogas plant reducing dependence on the firewood, International the News", Karachi, No.54 , 2012, pp 42-53.

[7] Wiley, P.E., Campbell, J. \& McKuin, B., , "Production of Biodiesel and Biogas from Algae": A Review of Process Train Options, Water Environment Research, 2011, pp 326-338.

[8] Santhi Mary Antony. A., Godwin Immanuel.D, "A novel single stage AC/DC PFC converter for renewable energy sources “, Journal of Green Engineering Volume 10,Issue 2,Feb 2020,pp 480493.

[9] Wilkie, A.C., Smith, P.H. and Bordeaux, F.M.” An economical bio-reactor for evaluating biogas potential of particulate biomass. Bio-resource Technology", 2004, pp103-109. 